\title{
Comparative genome analysis of the Lactobacillus brevis species
}

\author{
Marine Feyereisen ${ }^{1} \mathbb{B}$, Jennifer Mahony ${ }^{1,2}$, Philip Kelleher ${ }^{1}$, Richard John Roberts ${ }^{3}$, Tadhg O'Sullivan", \\ Jan-Maarten A. Geertman ${ }^{4}$ and Douwe van Sinderen ${ }^{1,2^{*}}$
}

\begin{abstract}
Background: Lactobacillus brevis is a member of the lactic acid bacteria $(L A B)$, and strains of L. brevis have been isolated from silage, as well as from fermented cabbage and other fermented foods. However, this bacterium is also commonly associated with bacterial spoilage of beer.

Results: In the current study, complete genome sequences of six isolated $L$. brevis strains were determined. Five of these L. brevis strains were isolated from beer (three isolates) or the brewing environment (two isolates), and were characterized as beer-spoilers or non-beer spoilers, respectively, while the sixth isolate had previously been isolated from silage. The genomic features of $19 \mathrm{~L}$. brevis strains, encompassing the six L. brevis strains described in this study and thirteen $L$. brevis strains for which complete genome sequences were available in public databases, were analyzed with particular attention to evolutionary aspects and adaptation to beer.

Conclusions: Comparative genomic analysis highlighted evolution of the taxon allowing niche colonization, notably adaptation to the beer environment, with approximately 50 chromosomal genes acquired by L. brevis beerspoiler strains representing approximately $2 \%$ of their total chromosomal genetic content. These genes primarily encode proteins that are putatively involved in oxidation-reduction reactions, transcription regulation or membrane transport, functions that may be crucial to survive the harsh conditions associated with beer. The study emphasized the role of plasmids in beer spoilage with a number of unique genes identified among L. brevis beer-spoiler strains.
\end{abstract}

Keywords: Lactobacillus brevis, SMRT sequencing, Genomics, Pan-genome, Beer adaptation, Beer spoilage

\section{Background}

Lactobacillus brevis is a member of the lactic acid bacteria $(\mathrm{LAB})$, which are catalase-negative, non-sporulating, non-motile, rod or coccus-shaped Gram-positive bacteria. L. brevis grows optimally at $30^{\circ} \mathrm{C}$ and within a $\mathrm{pH}$ range of 4 to 6 [1-3]. It is an obligatory hetero-fermentative bacterium producing lactic acid, carbon dioxide and ethanol and/or acetic acid [1-3]. Using phylogenomic and comparative genomic analysis Duar et al. studied the relatedness within the Lactobacillus genus in light of their natural habitat in order to understand their evolutionary history [4]. They assigned lactobacilli species into three main lifestyle categories: free living (environmental and plant isolates), host adapted or as "nomadic" [4].

\footnotetext{
* Correspondence: d.vansinderen@ucc.ie

${ }^{1}$ School of Microbiology, University College Cork, Cork, Ireland

${ }^{2}$ APC Microbiome Ireland, University College Cork, Cork, Ireland

Full list of author information is available at the end of the article
}

Sequenced genomes of the Lactobacillus genus range in size from 1.27 (L. iners) to 4.91 (L. parakefiri) Mbp [4].

L. brevis has been isolated from silage, as well as from fermented cabbage and other fermented foods [5, 6], and is assigned to the free-living lifestyle group of lactobacilli [4]. L. brevis strains, among other lactobacilli, are of particular interest as they have been granted Qualified Presumption of Safety (QPS) status and consequently have been widely used in the production of fermented foods $[1$, 7]. In addition to their application in food fermentations they are purported to have potential as health-promoting or probiotic bacteria $[1,7]$. In contrast to these positive attributes, $L$. brevis strains have also been reported as the causative agent of food or beverage spoilage, in particular of beer $[8,9]$. LAB species are reported to cause approximately $70 \%$ of microbial beer-spoilage incidents, and among this group L. brevis isolates are particularly problematic [10-12]. They are associated with the production of malodorous compounds, acidity and/or turbidity with 
negative impacts on the organoleptic properties of the final product. Bacterial spoilage of beer may result in product withdrawal or recall with concomitant economic losses for the brewing industry [10-12]. Beer spoilage by Gram-positive bacteria has been studied previously and the main mechanism of hop resistance known so far involves an active extrusion of the toxic compound using transporters identified as: (a) HorA which functions as an ABC-type multidrug transporter to expel hop compounds, in particular iso- $\alpha$-acids, from the bacterial cytoplasm, (b) HorC a proton motive force-dependent hop excretion transporter, and (c) the $\mathrm{H}^{+}$-ATPase which increases the pumping of protons released from the hop compounds [13-15]. The transmembrane protein HitA is also thought to play a role in the transport of divalent cations, where iso- $\alpha$-acids exchange protons for cellular divalent cations such as $\mathrm{Mn}^{2+}[16]$.

To date a number of comparative genome studies of the Lactobacillus genus have been described [1, 17-19], some of which have provided insights into the taxonomy of the Lactobacillus genus [3, 7], or its fermentation capabilities [3]. Carbohydrate metabolism has been assessed in several Lactobacillus species LAB such as L. casei or L. plantarum [2]. However, a broad comparative genome analysis of the $L$. brevis species has as yet not been undertaken. Recent advances in next generation sequencing technologies has facilitated a rapid surge in the number of bacterial genomes now available for comparative analysis within a genus or a species.

In the current study, Single-Molecule-Real-Time (SMRT) sequencing technology $[20,21]$ was employed to generate the complete genome sequence of an additional six L. brevis strains isolated from silage and the brewery environment. Using the dataset of 19 complete chromosomal sequences, a comparative genome analysis of the $L$. brevis taxon was undertaken through an assessment of the phylogeny, pan- and core-genome, and niche adaptation with particular emphasis on adaptation to the brewing environment. The importance of plasmids was also investigated in relation to beer spoilage ability.

\section{Results and discussion}

\section{Isolation of $L$. brevis strains}

Six L. brevis strains were isolated and included as part of the study, with the aim of expanding the collection of $L$. brevis genome sequences currently available, as well as studying their ability to grow and colonize harsh environments such as beer. Three L. brevis strains were isolated from beer and characterized as beer-spoilers based on their ability to grow in beer. Two additional $L$. brevis strains were isolated from the brewing environment, yet lack the ability to grow in beer and are thus not classified as beer-spoilers (Table 1 and Fig. 1). In addition, the sixth $L$. brevis strain sequenced as part of this study originates from silage [22] and was included as a non-brewing environmental isolate (Table 1). The different $L$. brevis isolates showed different colony morphology ranging from a dry irregular colony type for $L$. brevis UCCLBBS449 and UCCLB95 to a slimy and ropy colony type for UCCLBBS124 (Table 1). Plasmid profiling of the different isolates revealed a distinct plasmid content for each isolate. Growth curves in MRS broth demonstrated the unique growth profiles of the individual isolates confirming that the isolates were distinct from each other. Furthermore, only L. brevis UCCLB95, UCCLBBS124 and UCCLBBS449 were characterized as beer-spoilers having the ability to survive and grow in beer, while $L$. brevis SA-C12, UCCLB521 and UCCLB556 were defined as non-beer-spoilers (Table 1 and Fig. 1).

\section{General genome features}

The complete chromosomal sequences of nineteen $L$. brevis strains were selected for analysis, thirteen of which available at that time were obtained from the NCBI database, while the remaining six were sequenced as part of this study using SMRT sequencing technology (Table 2). These 19 selected $L$. brevis strains had been isolated from different ecological niches: silage, fermented food, animal's gut and the brewery environment (Table 2). The general features of the $19 \mathrm{~L}$. brevis genomes are indicated in Table 3 and include an average chromosome length of $2.49 \mathrm{Mbp}$ (ranging from 2.27 to $2.79 \mathrm{Mbp}$ ) and a $\mathrm{G}+\mathrm{C}$ content of $46 \%$. An average of 2338 predicted CDSs (Coding Sequences) per chromosome were identified to which approximately $78.3 \%$ could be assigned a function based on in silico predictions using BLAST (Basic Alignment Search Tool), while the remaining $21.7 \%$ were annotated as hypothetical proteins (Table 3). A type II CRISPR-Cas (Clustered Regularly Interspaced Short Palindromic Repeats) locus was found in the chromosome of L. brevis BGP6, L. brevis NPS-QW145 and L. brevis SRCM101106 where variability was observed in the spacer region, distinct spacers were observed in each of these three $L$. brevis strains suggesting an active system acquiring unique and various spacers for protection against invading DNA over time. Conversely, in the chromosome of L. brevis TMW1.2112 and L. brevis TMW1.2113 ten identical spacers were detected suggesting that these two strains are clonal or that this CRISPR-Cas system is inactive, and that these common spacers originate from a common ancestor that acquired genetic material from viruses/plasmids that it encountered in the past [23]. The L. brevis strain ZLB004 chromosome revealed the presence of four CRISPR locus, one was associated to a type I-E CRISPR-Cas system, a second one was associated to a type II CRISPR-Cas system both potentially active 
Table 1 Isolation of L. brevis strains

\begin{tabular}{|c|c|c|c|c|c|}
\hline Isolation source & L. brevis & Colony morphology & Plasmids & Ability to grow in beer & Spoiled beer characteristics \\
\hline Silage & SA-C12 & Rounded & 2 & No & $\mathrm{N} / \mathrm{A}$ \\
\hline Brewery & UCCLB521 & Rounded & 5 & No & N/A \\
\hline Brewery & UCCLB556 & Rounded & 7 & No & $\mathrm{N} / \mathrm{A}$ \\
\hline Beer & UCCLB95 & Dry, irregular edges & 2 & Yes & Turbid \\
\hline Beer & UCCLBBS124 & Slimy, ropy, rounded & 4 & Yes & Slimy, ropy, turbid \\
\hline Beer & UCCLBBS449 & Dry, irregular edges & 9 & Yes & Turbid \\
\hline
\end{tabular}

N/A not applicable

systems. The two other CRISPR locus were not associated to any CRISPR-Cas proteins suggesting inactive system.

PacBio SMRT sequencing was used to determine the diversity and frequency of methylated motifs recognized by Restriction Modification (R/M) systems within the six newly sequenced and annotated $L$. brevis strains as part of this study. R/M systems constitute one of the biological barriers exerted by a strain against foreign DNA [24]. This analysis revealed the presence of various m6A motifs and allowed the identification of three motifs assignable to Type I R/M system and six motifs assignable to Type II R/M system (Table 4). The presence of specific methylated motifs was linked to the presence of specific $\mathrm{R} / \mathrm{M}$ systems in the corresponding $L$. brevis strains (Table 4). Somewhat surprisingly, L. brevis UCCLB95 does not appear to encode any R/M systems.

\section{The predicted mobilome of $L$. brevis}

All complete chromosome sequences were analyzed for the presence of mobile elements such as IS elements and genes specified as encoding transposases. This analysis indicates that $L$. brevis strains UCCLBBS449 and UCCLB95 contain the highest number of insertion sequence (IS) elements/transposases, 114 and 132, respectively (Table 3).
The genome sequences were also investigated for prophages, revealing various predicted intact or partial prophage regions (Table 3), displaying in most cases similarity to the published $L$. brevis temperate bacteriophage LBR48 [25]. The plasmid content of the L. brevis strains is detailed below.

\section{Phylogenetic analysis}

The phylogenetic relationship between the genomes of the nineteen $L$. brevis strains were investigated by a comparative analysis of their 16S rRNA sequences (Fig. 2a). The resulting phylogenetic tree distinguishes five clades (clades A through to E). Clade A represents two L. brevis beer-spoiling strains UCCLB95 and UCCLBBS449 both isolated from spoiled beer, displaying slow growth in nutritive media or beer (.

Table 1 and Fig. 1). Clade B encompasses three L. brevis strains: $L$. brevis SRCM101106 isolated from food $L$. brevis BDGP6 isolated from the gut of a drosophila and L. brevis NCTC13768 from an unknown isolation source. Clade C is represented by six $L$. brevis strains, of which one was isolated from food (L. brevis SRCM101174), three from silage (L. brevis SA-C12, ATCC 367 and 100D8) and two strains (L. brevis UCCLB521 and UCCLB556), both isolated from the
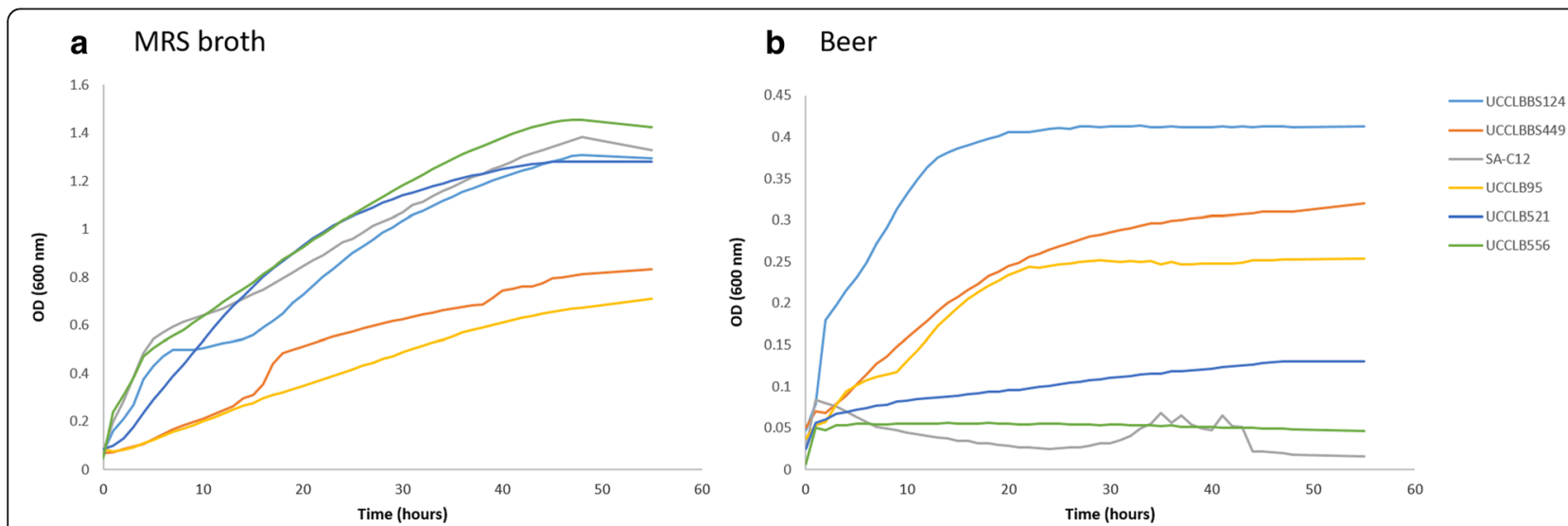

Fig. 1 Growth profile of L. brevis strains sequenced in this study. Growth profile of L. brevis strains UCCLBBS124, UCCLBBS4449, UCCLB95, UCCLB521, UCCLB556 and SA-C12 in (a) MRS broth or (b) beer. Growth curves were performed in triplicate and the average of those measurements is displayed in the graph above 
Table 2 Lactobacillus brevis strains and/or genomes used in this study

\begin{tabular}{|c|c|c|c|c|}
\hline Strain name & Genbank accession & Ecological niche & Year & Citation \\
\hline $100 \mathrm{D} 8$ & CP015338 & Rye silage (South Korea) & 2016 & \\
\hline ATCC 367 & CP000416 & Sourdough/Silage starter culture & 2006 & [5] \\
\hline BDGP6 & CP024635 & Drosophila melanogaster female gut & 2015 & \\
\hline KB290 & AP012167 & Suguki (fermented vegetable) & 2013 & [49] \\
\hline NPS-QW-145 & CP015398 & Traditional Korean Kimchi (Hong-Kong) & 2016 & [50] \\
\hline NCTC13768 & LS483405 & Unknown & & \\
\hline $\mathrm{SA}-\mathrm{C} 12$ & СР031185 & Silage (Ireland) & 2008 & [22] \\
\hline SRCM101106 & СР021674 & Food (South Korea) & 2017 & \\
\hline SRCM101174 & CP021479 & Food (South Korea) & 2017 & \\
\hline TMW 1.2108 & СР019734 & Wheat beer (Germany) & 2016 & \\
\hline TMW 1.2111 & CP019743 & Wheat beer (Germany) & 2016 & \\
\hline TMW 1.2112 & СР016797 & Wheat beer (Germany) & 2016 & \\
\hline TMW 1.2113 & CP019750 & Brewery-associated surface (Germany) & 2016 & \\
\hline UCCLB521 & CP031208 & Brewery environment (The Netherlands) & 2013 & This study \\
\hline UCCLB556 & СР031174 & Brewery environment (The Netherlands) & 2014 & This study \\
\hline UCCLB95 & CP031182 & Beer (The Netherlands) & 2001 & This study \\
\hline UCCLBBS124 & СР031169 & Beer keg (Singapore) & 2003 & This study \\
\hline UCCLBBS449 & CP031198 & Unpasteurised beer (The Netherlands) & 1994 & This study \\
\hline ZLB004 & CP021456 & Pig's feces & 2010 & \\
\hline
\end{tabular}

Table 3 General chromosomal features and plasmid content among L. brevis strains

\begin{tabular}{|c|c|c|c|c|c|c|c|c|c|c|c|}
\hline $\begin{array}{l}\text { L. brevis } \\
\text { strain }\end{array}$ & $\begin{array}{l}\text { Chromosome } \\
\text { length (Mbp) }\end{array}$ & CDS & $\begin{array}{l}\text { tRNA } \\
\text { features }\end{array}$ & $\begin{array}{l}\text { rRNA } \\
\text { features }\end{array}$ & $\begin{array}{l}\text { Hypothetical } \\
\text { proteins } \%\end{array}$ & $\begin{array}{l}\text { Assigned } \\
\text { function \% }\end{array}$ & $\begin{array}{l}\text { IS elements/ } \\
\text { transposases }\end{array}$ & Prophage & CRISPR & GC \% & $\begin{array}{l}\text { Plasmids (Ranging } \\
\text { size Kb) }\end{array}$ \\
\hline $100 \mathrm{D} 8$ & 2.35 & 2228 & 66 & 15 & 21.2 & 78.8 & 25 & $1 \ln ^{\mathrm{a}} 3 \mathrm{~Pa}^{\mathrm{b}}$ & - & 46.1 & $3(39.9-45.1)$ \\
\hline ATCC 367 & 2.29 & 2133 & 65 & 15 & 20.8 & 79.2 & 34 & $1 \ln$ & - & 46.2 & $2(13.4-35.6)$ \\
\hline BDGP6 & 2.79 & 2674 & 71 & 15 & 23.1 & 76.9 & 24 & $4 \ln 3 \mathrm{~Pa}$ & 1 & 46.6 & - \\
\hline KB290 & 2.40 & 2308 & 64 & 15 & 21.4 & 78.6 & 50 & $2 \ln 2 \mathrm{~Pa}$ & - & 46.1 & $9(5.9-42.4)$ \\
\hline NCTC13768 & 2.49 & 2413 & 65 & 15 & 15.0 & 85.0 & 3 & $1 \mathrm{~Pa}$ & - & 46.0 & - \\
\hline NPS-QW-145 & 2.55 & 2406 & 62 & 13 & 21.5 & 78.5 & 5 & $3 \mathrm{~Pa}$ & 1 & 45.8 & - \\
\hline SA-C12 & 2.44 & 2344 & 66 & 15 & 23.2 & 76.7 & 42 & $2 \ln 3 \mathrm{~Pa}$ & - & 45.9 & $2(24.8-43.6)$ \\
\hline SRCM101106 & 2.44 & 2379 & 67 & 15 & 23.0 & 77.0 & 46 & $3 \ln 4 \mathrm{~Pa}$ & 1 & 45.9 & $4(16.0-36.2)$ \\
\hline SRCM101174 & 2.41 & 2353 & 68 & 15 & 24.0 & 76.0 & 37 & $3 \ln 2 \mathrm{~Pa}$ & - & 46.1 & $5(9.4-50.4)$ \\
\hline TMW 1.2108 & 2.57 & 2448 & 66 & 15 & 22.8 & 77.2 & 17 & $2 \ln$ & - & 45.8 & $8(5.1-107.0)$ \\
\hline TMW 1.2111 & 2.57 & 2458 & 66 & 15 & 21.8 & 78.2 & 22 & $2 \ln$ & - & 45.8 & $6(8.2-107.0)$ \\
\hline TMW 1.2112 & 2.49 & 2283 & 65 & 15 & 19.6 & 80.4 & 29 & $1 \ln 1 \mathrm{~Pa}$ & 1 & 46.0 & $5(8.5-59.7)$ \\
\hline TMW 1.2113 & 2.54 & 2376 & 69 & 15 & 22.5 & 77.5 & 30 & $2 \ln$ & 1 & 45.9 & $4(8.5-46.6)$ \\
\hline UCCLB521 & 2.27 & 2088 & 62 & 15 & 20.0 & 80.0 & 32 & $2 \mathrm{~Pa}$ & - & 46.3 & $5(11.3-43.8)$ \\
\hline UCCLB556 & 2.38 & 2201 & 66 & 18 & 22.8 & 77.2 & 32 & $1 \mathrm{~Pa}$ & - & 46.1 & $7(4.3-68.4)$ \\
\hline UCCLB95 & 2.51 & 2283 & 65 & 15 & 22.7 & 77.3 & 132 & $1 \mathrm{In} 1 \mathrm{~Pa}$ & - & 45.9 & $2(3.5-14.0)$ \\
\hline UCCLBBS124 & 2.61 & 2442 & 66 & 15 & 21.8 & 78.2 & 60 & $1 \ln 2 \mathrm{~Pa}$ & - & 45.8 & $4(21.0-49.6)$ \\
\hline UCCLBBS449 & 2.58 & 2404 & 66 & 15 & 21.1 & 78.9 & 114 & $1 \ln 3 \mathrm{~Pa}$ & - & 45.8 & $9(2.8-66.8)$ \\
\hline ZLB004 & 2.66 & 2207 & 64 & 15 & 24.0 & 76.0 & 29 & $1 \ln$ & 2 & 46.0 & $5(16.7-78.1)$ \\
\hline Average & 2.49 & 2338 & 66 & 15 & 21.7 & 78.3 & 40 & $1.4 \ln 1.6 \mathrm{~Pa}$ & - & 46.0 & 5 \\
\hline
\end{tabular}


Table 4 L. brevis methyltransferases with their assigned recognition sequence

\begin{tabular}{llll}
\hline L. brevis strain & Enzyme & Recognition sequence/motif & R/M type \\
\hline UCCLBBS124 & Lbr124II & CATCNAC & $\|$ \\
& M.Lbr124l & YTCA(N7)TTRG & । \\
UCCLB521 & M.Lbr521I & AGG(N6)TTC & । \\
& Not assigned & GATC & $\|$ \\
UCCLB556 & M.Lbr556l & RTCA(N9)TCC & । \\
UCCLBBS449 & Lbr449| & AGCCAG & $\|$ \\
& Not assigned & CTTGCA & $\|$ \\
UCCLB95 & None detected & & \\
SA-C12 & M1.LbrSAC12IP & GAGGC & $\|$ \\
& M2.LbrSAC121 & GAGGC & $\|$ \\
\hline
\end{tabular}

Bold: $\mathrm{m} 6 \mathrm{~A}$

brewing environment, yet unable to survive and grow in beer (Table 1). These latter two strains may have been introduced into the brewery through raw materials such as cereal grains thus explaining the observed phylogenetic relation to the silage $L$. brevis isolate SA-C12. Clade D includes five L. brevis strains, all retrieved as beer-spoiler strains from the brewing environment, and all exhibiting a slimy, ropy phenotype (Table 1) [9]. Clade $\mathrm{E}$ gathers three L. brevis strains, two isolated from fermented food (L. brevis KB290 and NPS-QW-145) as well as L. brevis ZLB004 isolated from pig's feces.
In order to obtain a more refined view of the phylogeny of the 19 analyzed strains, a so-called phylogenetic supertree was constructed based on 631 conserved orthologous proteins that had been identified as single-copy genes conserved across all investigated chromosomal sequences $(19 \mathrm{~L}$. brevis strains and Enterococcus faecalis V583 as an outgroup) [26, 27]. This supertree does not display distinct clades separating the L. brevis strains in different groups as was observed with the 16S rRNA phylogenetic tree, suggesting a close relatedness within the species (Fig. 2b). However, upon close inspection of this phylogenetic tree, it appears that $L$. brevis strains isolated from food and silage cluster on one branch of the tree, while $L$. brevis brewery isolates cluster on another. The $L$. brevis strains isolated from gut microbiota BDGP6 and ZLB004 as well as L. brevis strains NCTC13768 and 100D8 gather in a smaller clade.

\section{Pan/core-genome analysis}

A pan-genome analysis was performed in order to determine the total number of distinct genes present on the combined chromosomal sequences of the analyzed $L$. brevis strains. The pan-genome curve displays an asymptotic trend, growing with an average rate of 136 genes per genome in the first nine iterations, then the number of new genes decreased leading to a total pan-genome content of 3968 genes (Fig. 3). The mathematical function displayed on the graph reveals an exponential value lower than 0.5 indicating that the pan-genome is in a closed state. The core genome was determined to

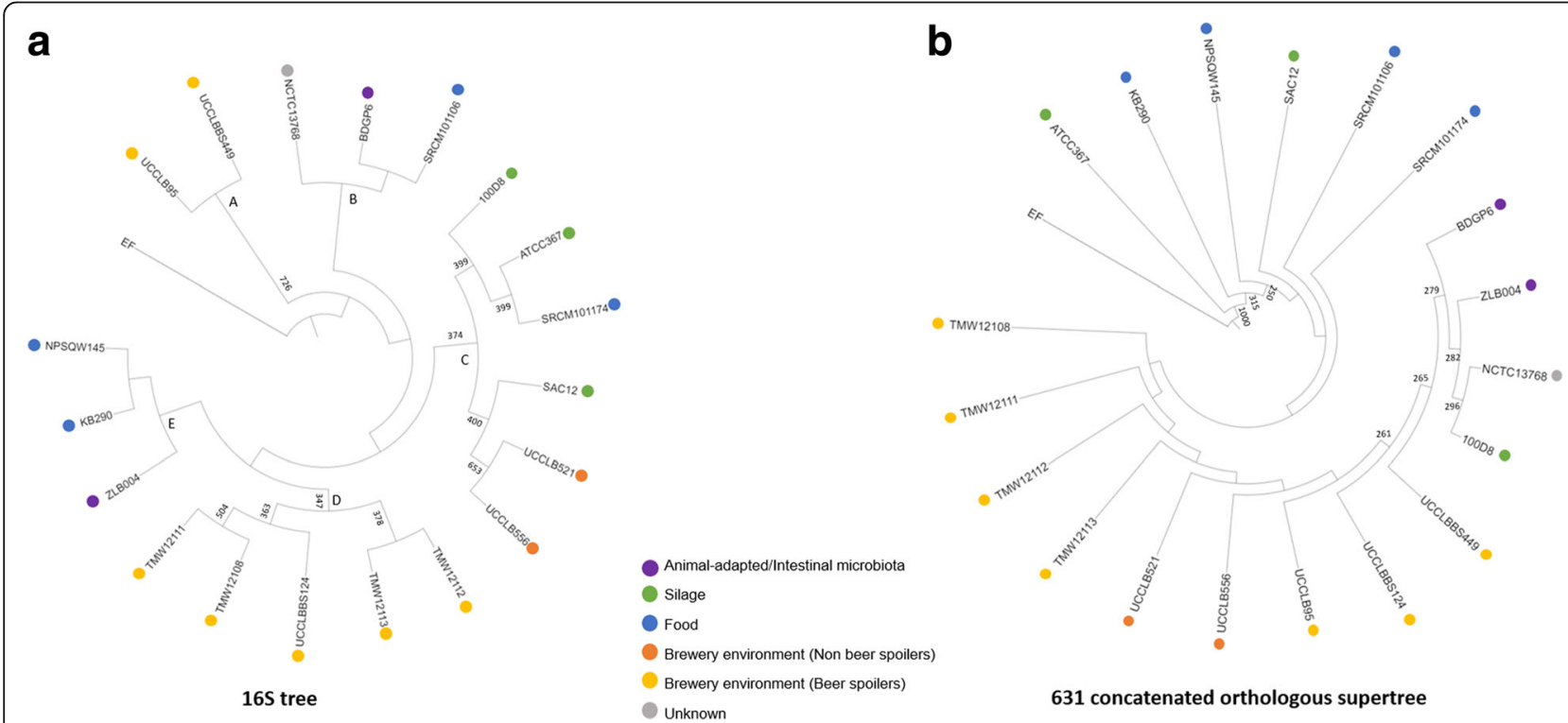

Fig. 2 Phylogenetic analysis of L. brevis species. a $16 S$ ribosomal tree obtained from the alignment of the $16 \mathrm{~S}$ rRNA-encoding genes of $19 \mathrm{~L}$. brevis strains, bootstrapped $\times 1000$ replicates, values $>250$ are indicated. The $16 \mathrm{~S}$ rRNA sequence of Enterococcus faecalis V583 (noted EF on the figure) was used as an outgroup. b Phylogenetic supertree obtained from the alignment of 631 orthologous genes among the $19 \mathrm{~L}$. brevis strains used in this study as well as in Enterococcus faecalis V583 (noted EF on the figure) which was used as an outgroup, bootstrapped $\times 1000$ replicates, values $>250$ are indicated. Source of isolation for the different $L$. brevis strains are also indicated 


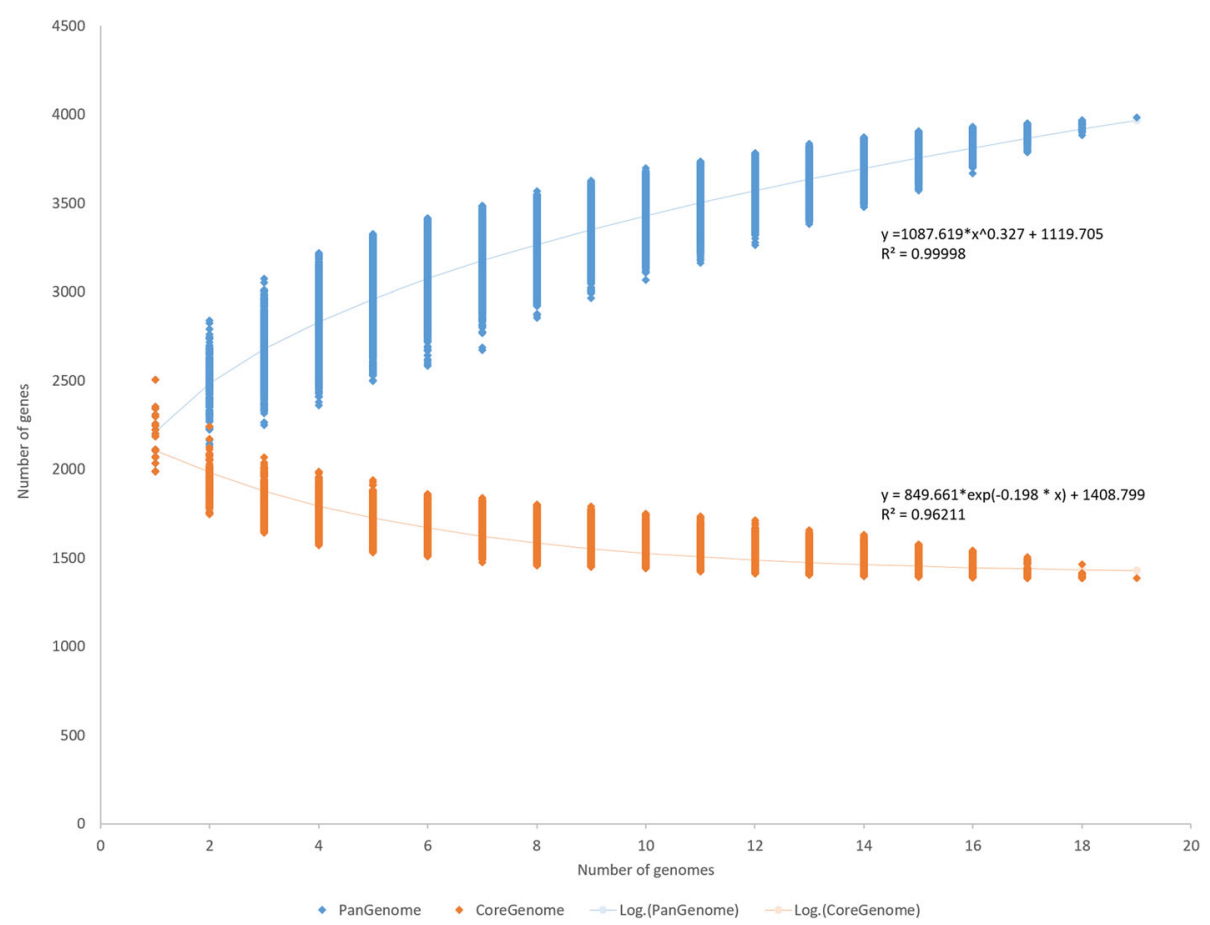

Fig. 3 Pan- and core-genome of L. brevis. Accumulated number of new genes in the L. brevis pan-genome plotted against the number of new genomes added as well as accumulated number of genes attributed to the core-genome plotted against the number of genomes added. Deduced mathematical functions are also displayed on the graph

encompass 1428 genes (Fig. 3). As an overall result, both analyses indicate a closed pan-genome for L. brevis species, while also indicating that a sufficient number of strains had been included to adequately describe the genetic repertoire of the L. brevis species.

\section{Comparative analysis of orthologous genes}

The comparative analysis used in this study was based on chromosomal sequences. The core genome of 1428 genes is divided in 1170 orthologous gene families (single copy) and 258 paralogous gene families (multi-copy). Unique gene families to each chromosome were also recorded and 246 unique gene families were identified across the nineteen L. brevis strains (Fig. 4a). Functional assignment efforts revealed that $75.2 \%$ of the unique gene families encoded proteins of unknown function (hypothetical proteins), while $4.5 \%$ encoded (pro)phage-related proteins. The remaining unique gene families encode proteins that could benefit the fitness of the strain such as CRISPR-Cas system (e.g. Type I-E CRISPR Cas system in L. brevis ZLB004), restriction-modification systems (e.g. Type I R/M system in L. brevis strain UCCLBBS124), or cell wall polysaccharide synthesis (e.g. genes predicted to encode glycosyltransferases and a polysaccharide polymerase only found in the L. brevis strain NPS-QW-145).

In order to further investigate the functionality and diversity encoded by the core and dispensable genomes, a
Cluster of Orthologous Group (COG) analysis was employed. The genome content of the 19 selected $L$. brevis strains was classified into different groups depending on their function. More than $75 \%$ were predicted to be involved in housekeeping functions, vital for the strain to grow such as those participating in transcription or translation. Approximately $16 \%$ of the genes were assigned to COG groups with only a general function predicted or of unknown function (Fig. 4b).

\section{Evolution and adaptation to beer environment}

When plotting the number of CDSs as a function of genome size for the different $L$. brevis strains, the group exhibiting the largest genome size as well as the highest number of CDS are L. brevis strains isolated from beer and characterized as beer-spoilers as well as the L. brevis strain BDGP6 displaying the biggest CDS number. $L$. brevis strains known to be beer-spoilers possess an average of 2385 CDS, while those isolated from food, silage, animal's gut and non-beer spoiling brewery isolates display an average of 2311 CDSs (Fig. 5). This observation suggests a link to adaptation to a new environment, i.e. the beer or brewery environment, which may have necessitated the acquisition of novel genes and corresponding functions in order to survive in this harsh environment. To understand if the beer-spoiling strains had acquired a specific set of genes or associated 


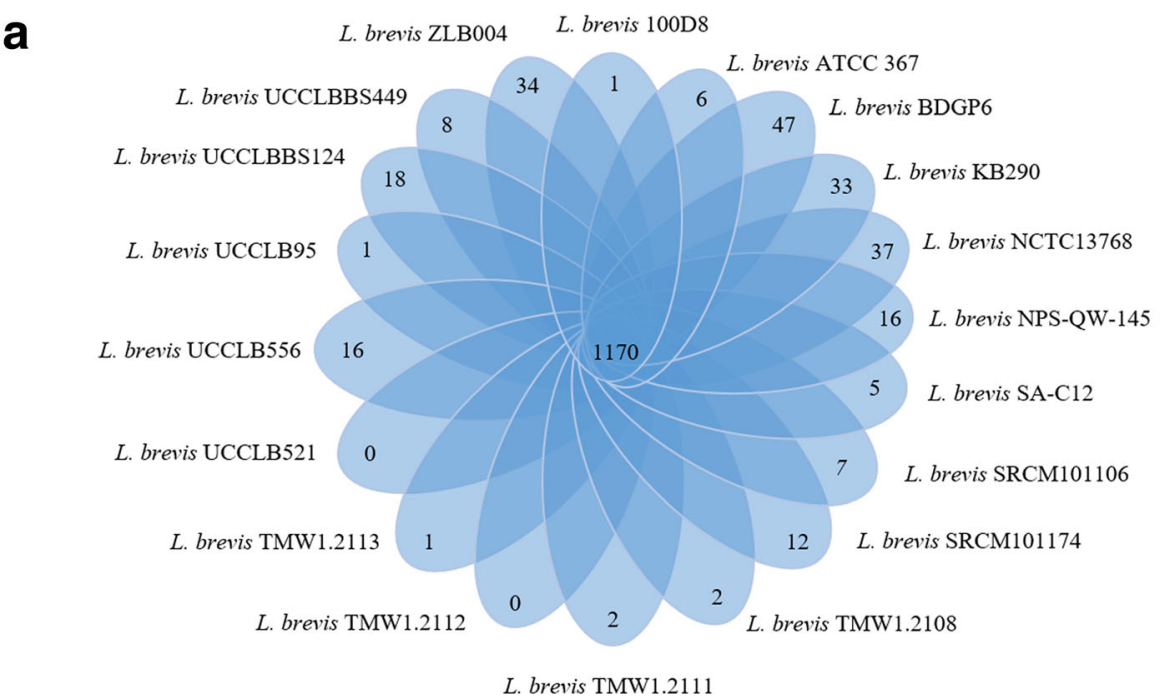

b

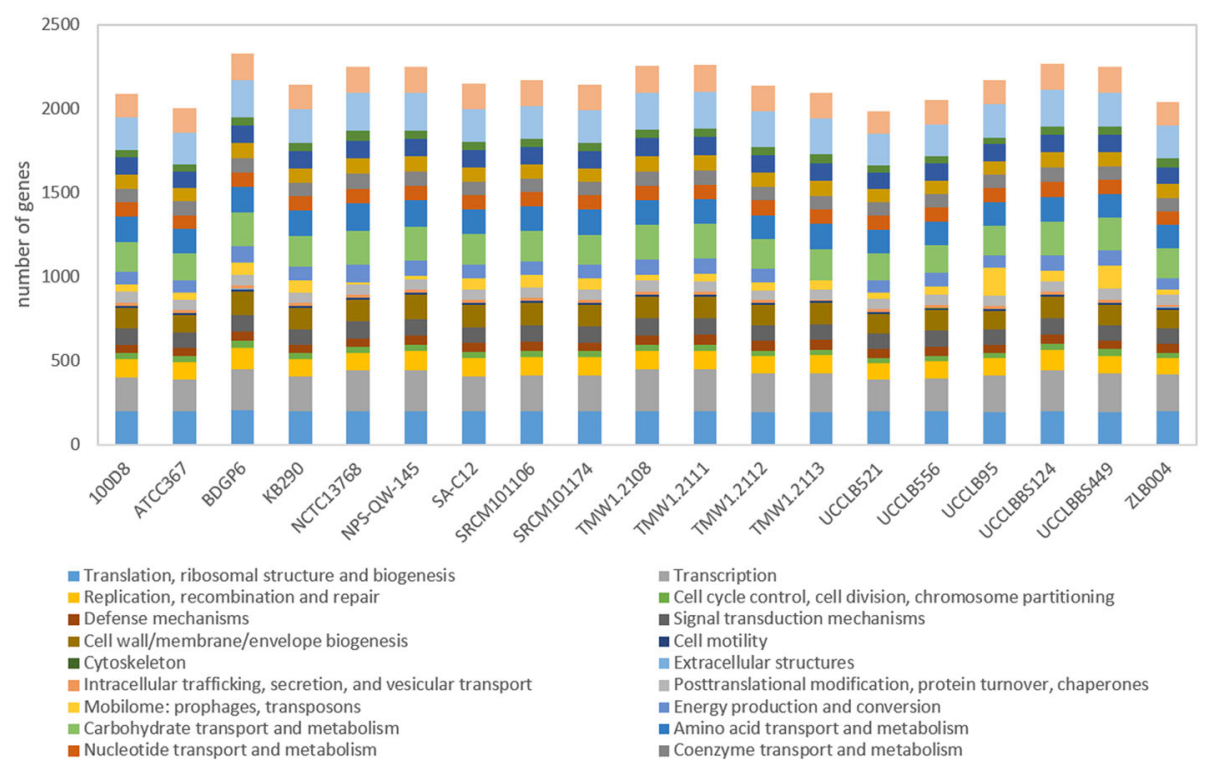

Fig. 4 Comparative genomics of chromosomal orthologous proteins in L. brevis. Panel a: Venn diagram representing the orthologous and unique gene families of 19 L. brevis strains obtained by MCL clustering. Panel b: Cluster of Orthologous Groups (COG) classification of L. brevis. Histograms represent COG predictions for each of the following 16 L. brevis isolates: L. brevis 100D8, L. brevis ATCC 367, L. brevis BDGP6, L. brevis KB290, L. brevis NCTC13768, L. brevis NPS-QW-145, L. brevis SA-C12, L. brevis SRCM101106, L. brevis SRCM101174, L. brevis TMW 1.2108, L. brevis TMW 1.2111, L. brevis TMW 1.2112, L. brevis TMW 1.2113, L. brevis UCCLB521, L. brevis UCCLB556, L. brevis UCCLB95, L. brevis UCCLBBS124, L. brevis UCCLBBS449, L. brevis ZLB004

functions, genes that may putatively be associated to beer adaptation were first predicted to be those that would be present in the genomes of at least four beer spoiling strains (Table 5). From this analysis, 58 genes of interest were highlighted as well as 26 hypothetical proteins. Out of these 58 genes, approximately $21 \%$ encode proteins related to oxido-reduction reactions (Flavodoxin, oxidoreductases and short-chain dehydrogenases), $22 \%$ are linked to transcription (transcriptional regulators, RNA polymerase sigma-24 subunit ECF subfamily),
$21 \%$ encode membrane and cell surface proteins and $14 \%$ are related to membrane transport (MFS transporter, permease, $\mathrm{ABC}$ transporters) (Table 5).

When exposed to beer, bacteria are subjected to various stresses, among them a low $\mathrm{pH}(3.8-4.7)$ and hop compounds [10]. When iso- $\alpha$-acids enter the cell cytoplasm, they dissociate into hop anions and protons decreasing the intracellular $\mathrm{pH}$ [10]. Therefore, bacteria would have to adapt in order to regulate their internal $\mathrm{pH}$ in order to survive [28-30]. Furthermore, in beer the 


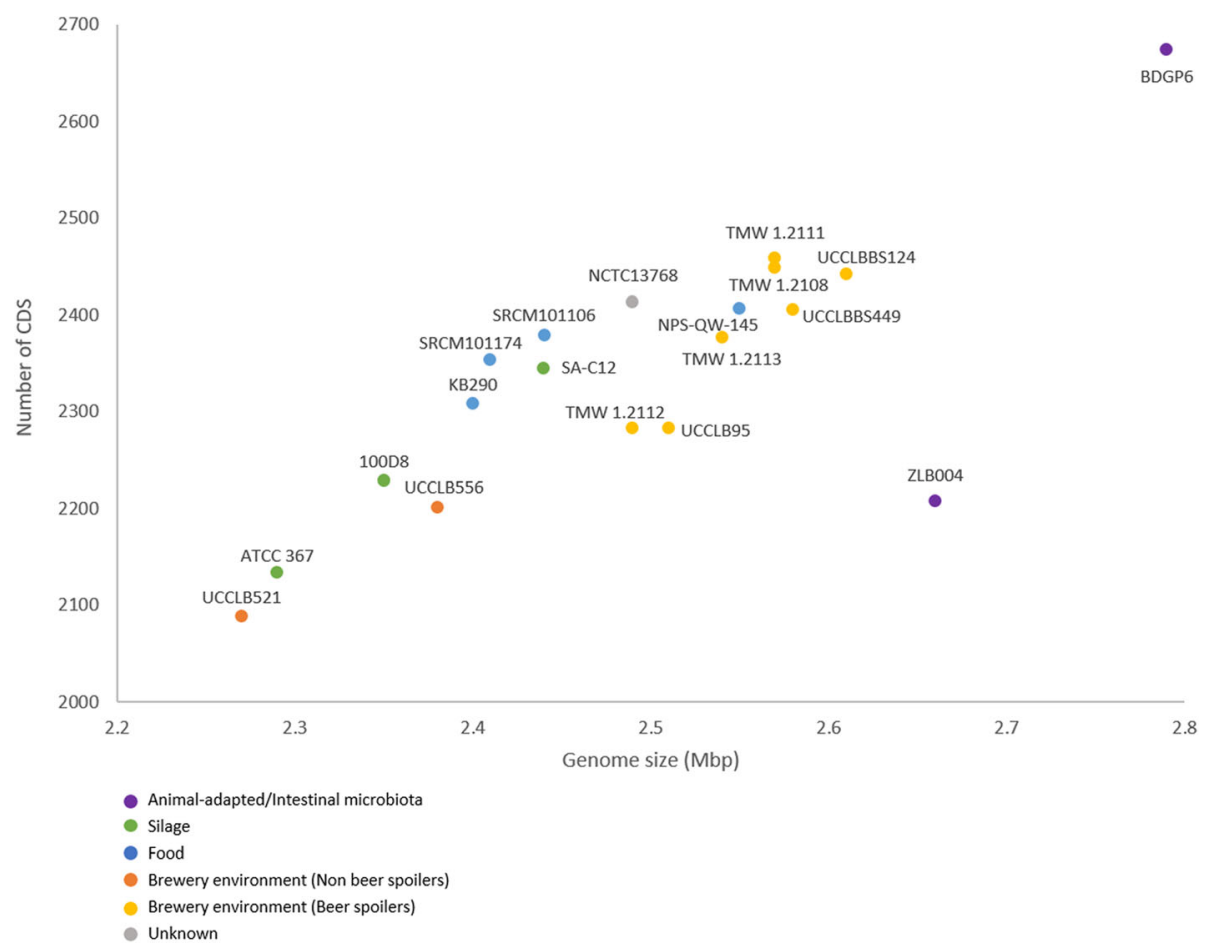

Fig. 5 Association between chromosome size and CDS number in nineteen L. brevis complete chromosomal sequences

presence of ethanol $(0.5-10 \% \mathrm{w} / \mathrm{w})$ causes oxidative stress in bacteria, this results in the production of Reactive Oxygen Species (ROS) such as hydrogen peroxide and free radicals leading to cell damage [31, 32]. Despite the stress and harsh environment imposed by the beer environment, some bacteria have evolved and acclimatized to this new medium. It may thus be possible that some of the L. brevis strains acquired additional functions which allow them to grow and survive in beer and which has led to an increased genome size. The fact that $21 \%$ of these chromosomal genes encode proteins related to redox reactions is of interest and suggests a link between $L$. brevis beer-spoiler strains and oxidative stress response. Six of the 12 genes that encode functions relating to oxido-reduction reactions present in at least four beer-spoiler $L$. brevis strains are predicted to encode NADH oxidoreductases and short-chain dehydrogenases/reductases (SDRs). These proteins are part of the large family of $\mathrm{NAD}(\mathrm{P})(\mathrm{H})$-dependent oxidoreductases and are believed to behave as scaffold proteins for an $\operatorname{NAD}(\mathrm{P})(\mathrm{H})$ redox sensor system [33]. In previous studies, the role of SDRs during oxidative stress was highlighted in species such as Bacillus subtilis where they are required for survival in severe ethanol stress [34], or in Burkholderia pseudomallei during salt stress [35].

Furthermore, 22\% of the chromosomal genes that seem to be specifically associated with beer-spoiling $L$. brevis strains are linked to transcriptional regulation, suggesting that these regulators act on specific genes to control their expression and confer an advantage when present in beer. It would be interesting to study which genes are affected by these transcriptional regulators to assess the mechanisms employed to survive in this harsh environment. Of the $L$. brevis beer-spoiler specific chromosomal genes $21 \%$ encode membrane and cell surface proteins suggesting an adaptation to survive in the harsh beer environment. 14\% encode proteins associated with membrane transport such as permeases and $A B C$ transporters suggesting exchange between the strain and its environment and possibly a role in extrusion where the $L$. brevis isolate would expel protons or iso- $\alpha$-acids in order to survive and thrive in beer, as has been described previously $[10,13,15]$.

Interestingly some of the chromosomal genes identified among $L$. brevis beer-spoiler strains in this analysis had also been highlighted in a previous study as beer-spoilage diagnostic marker genes (DMG) [36]. These genes are predicted to code for an oligogalacturonide transporter, a short chain dehydrogenase and a RNA polymerase sigma factor ECF subfamily, which reinforces the hypothesis for their involvement in beer spoilage adaptation.

The role of plasmids in adaptation to beer environment Different proteins involved in beer spoilage have been identified on plasmids indicating the importance of 
Table 5 List of genes identified in the chromosome sequence of at least four L. brevis beer spoiler strains. 26 genes coding for hypothetical proteins were also identified

\begin{tabular}{|c|c|c|c|c|c|c|c|}
\hline \multirow[t]{2}{*}{ COG category and protein function } & \multicolumn{7}{|c|}{ L. brevis beer-spoiler strains } \\
\hline & TMW1.2108 & TMW1.2111 & TMW1.2112 & TMW1.2113 & UCCLB95 & UCCLBBS124 & UCCLBBS449 \\
\hline & \multicolumn{7}{|c|}{ Energy production and conversion } \\
\hline Flavodoxin & + & + & + & + & + & + & + \\
\hline NADH-Flavin reductase & + & + & - & - & + & + & + \\
\hline Oxidoreductase & + & + & + & + & + & + & + \\
\hline NADPH:quinone reductase & + & + & - & - & + & + & + \\
\hline FMN-dependent NADH-azoreductase & + & + & - & - & + & + & + \\
\hline \multirow[t]{2}{*}{ Nitrobenzoate reductase } & + & + & - & - & + & + & + \\
\hline & \multicolumn{7}{|c|}{ Amino acid transport and metabolism } \\
\hline Shikimate dehydrogenase & + & + & + & + & + & + & + \\
\hline Acetyltransferase GNAT family & + & + & - & - & + & + & + \\
\hline \multirow[t]{2}{*}{ Serine O-acetyltransferase EC } & + & + & - & - & + & + & + \\
\hline & \multicolumn{7}{|c|}{ Carbohydrate transport and metabolism } \\
\hline MFS transporter & + & + & - & - & + & + & + \\
\hline Alpha-glucosidase & + & + & + & + & + & + & + \\
\hline lycoside hydrolase & + & + & - & - & - & + & + \\
\hline Hydrolase & + & + & + & + & + & + & + \\
\hline Transketolase & + & + & + & + & - & - & - \\
\hline MFS transporter & + & + & + & - & + & + & - \\
\hline PTS system2C IIA component 1 & + & + & - & - & + & + & + \\
\hline Putative integral membrane protein 1 & + & + & - & - & + & + & + \\
\hline PTS2C EIIB 1 & + & + & - & - & + & + & + \\
\hline PTS mannitol transporter subunit IIA & + & + & - & - & + & + & + \\
\hline \multirow[t]{2}{*}{ Putative oligogalacturonide transporter } & + & + & + & + & + & - & + \\
\hline & \multicolumn{7}{|c|}{ Coenzyme transport and metabolism } \\
\hline \multirow[t]{2}{*}{ 6-pyruvoyl tetrahydropterin synthase } & + & + & + & + & - & + & - \\
\hline & \multicolumn{7}{|c|}{ Lipid transport and metabolism } \\
\hline NADH peroxidase & + & + & + & + & + & + & + \\
\hline Peroxidase & + & + & - & - & + & + & + \\
\hline \multirow[t]{2}{*}{ Citrate lyase } & + & + & - & - & + & + & + \\
\hline & \multicolumn{7}{|l|}{ Transcription } \\
\hline Transcriptional regulator2C TetR family & + & + & - & - & + & + & + \\
\hline Transcriptional regulator & + & + & + & + & + & + & + \\
\hline Transcriptional regulator TetR family & + & + & - & - & + & + & + \\
\hline Transcriptional regulator & + & + & + & + & + & + & + \\
\hline Internalin-J & - & + & + & + & + & + & + \\
\hline RNA polymerase sigma-24 subunit ECF subfamily & + & + & + & + & + & + & + \\
\hline ECF-type sigma factor negative effector & + & + & + & + & + & + & + \\
\hline Transcriptional regulator & + & + & + & + & + & + & + \\
\hline Transcriptional regulator MarR family & + & + & - & - & + & + & + \\
\hline Transcriptional regulator & + & + & - & - & + & + & + \\
\hline Transcriptional regulator MarR family & + & + & - & - & + & + & + \\
\hline Transcriptional regulator TetR & + & + & - & - & - & + & + \\
\hline
\end{tabular}


Table 5 List of genes identified in the chromosome sequence of at least four L. brevis beer spoiler strains. 26 genes coding for hypothetical proteins were also identified (Continued)

\begin{tabular}{|c|c|c|c|c|c|c|c|}
\hline \multirow[t]{2}{*}{ COG category and protein function } & \multicolumn{7}{|c|}{ L. brevis beer-spoiler strains } \\
\hline & TMW1.2108 & TMW1.2111 & TMW1.2112 & TMW1.2113 & UCCLB95 & UCCLBBS124 & UCCLBBS449 \\
\hline \multirow[t]{2}{*}{ Transcriptional regulator ArsR family } & + & + & - & - & + & + & + \\
\hline & \multicolumn{7}{|c|}{ Cell wall/membrane/envelope biogenesis } \\
\hline Membrane protein & + & + & - & + & - & + & - \\
\hline Cell surface protein & + & + & + & + & - & - & - \\
\hline Cell surface protein & + & + & - & - & - & + & + \\
\hline Endo polygalacturonase & + & + & + & + & - & - & + \\
\hline Glutamyl endopeptidase precursor & + & + & + & + & + & + & + \\
\hline NLP-P60 protein & + & + & + & + & + & + & + \\
\hline \multirow[t]{2}{*}{ Short-chain dehydrogenase-oxidoreductase } & + & + & - & - & + & + & + \\
\hline & \multicolumn{7}{|c|}{ Inorganic ion transport and metabolism } \\
\hline Permease & + & + & + & + & + & + & + \\
\hline Permease & + & + & + & + & + & - & + \\
\hline \multirow[t]{2}{*}{$\mathrm{Na}+-\mathrm{H}+$ antiporter } & + & + & - & - & + & + & - \\
\hline & \multicolumn{7}{|c|}{ General function prediction only } \\
\hline $\mathrm{NADPH}$-quinone reductase & + & + & + & + & + & + & + \\
\hline Short-chain dehydrogenase-oxidoreductase & + & + & + & + & + & + & + \\
\hline Short-chain dehydrogenase & + & + & + & + & + & + & - \\
\hline Cell surface adherence protein & - & - & + & + & + & + & + \\
\hline \multirow[t]{2}{*}{ Mucus-binding protein LPXTG-motif cell wall anchor } & + & + & + & + & + & - & + \\
\hline & \multicolumn{7}{|c|}{ Function unknown } \\
\hline Cell surface hydrolase & + & + & + & + & + & + & + \\
\hline Membrane protein & + & + & + & + & - & + & + \\
\hline \multirow[t]{2}{*}{ Cell surface protein } & + & + & - & - & + & + & + \\
\hline & \multicolumn{7}{|c|}{ Defence mechanisms } \\
\hline ABC transporter ATP-binding protein & + & + & + & + & + & + & + \\
\hline $\mathrm{ABC}$ transporter permease & + & + & + & + & + & + & + \\
\hline Prophage protein & + & + & + & + & - & - & + \\
\hline
\end{tabular}

+: gene present, -: gene absent

plasmids for bacterial strains in beer spoilage. This might suggest a role for plasmid mobilization and transfer between bacterial strains throughout evolution to adapt to a new environment such as beer.

The nineteen analyzed $L$. brevis strains were predicted to harbour up to nine plasmids with strains $L$. brevis KB290 and L. brevis UCCLBBS449 exhibiting the largest plasmid complements of the assessed strains. The plasmid size ranges from $2.8 \mathrm{~Kb}$ to $107.0 \mathrm{~Kb}$ (Table 3 ). The number of plasmids and their size do not appear to be linked to the isolation source of the L. brevis strains (e.g. four plasmids for L. brevis SRCM101106 versus nine plasmids for $L$. brevis KB290, both isolated from fermented food) or to the beer spoilage ability of the isolate (two plasmids for L. brevis UCCLB95 versus nine plasmids for $L$. brevis UCCLBBS449 both characterised as beer-spoilers).
Investigating analogies between plasmids among L. brevis beer-spoiler strains revealed that the plasmid content of $L$. brevis TMW1.2108 and L. brevis TMW1.2111 were very similar. Indeed, the six plasmids of L. brevis TMW1.2111 show at least $90 \%$ identity to seven of the eight plasmids contained by strain L. brevis TMW1.2108, with the exception of plasmid TMW1.2108-5. Similarly, L. brevis strains TMW1.2112 and TMW1.2113 present a close plasmid composition as the four plasmids of $L$. brevis TMW1.2113 are at least $90 \%$ identical to four out of five plasmids of $L$. brevis TMW1.2112 with the exception of plasmid TMW1.2112-1.

Out of the 38 plasmids shared between L. brevis beer-spoiler strains, only three plasmids seem to be unique, sharing less than $10 \%$ similarity with any other plasmid. These three plasmids were found in L. brevis 
UCCLBBS449 (UCCLBBS449_pF, UCCLBBS449_pH and UCCLBBS449_pI) and contain mostly genes coding for hypothetical proteins, replication proteins as well as genes coding for proteins involved in conjugation such as mobilization proteins and a relaxase.

Refined analysis of specific genes shared only between at least three L. brevis beer-spoiler strains, identified only twenty-five genes (Table 6). In this list of unique genes shared only between $L$. brevis beer-spoiler strains, the gene coding for the membrane protein HorC is noteworthy, as it is known to be involved in beer spoilage [14] and is present in all L. brevis beer-spoiler strains with the exception of L. brevis TMW1.2113.

Interestingly, the gene encoding the $\mathrm{ABC}$ transporter HorA [13] and present in L. brevis beer-spoiler strains TMW1.2108, TMW1.2111, TMW1.2113, UCCLBBS124 and UCCLBBS449 does not figure in this list as a similar protein can be found in plasmid sequences of the $L$. brevis strains KB290, SRCM101106 isolated from fermented food and L. brevis UCCLB556 isolated from the brewery and characterized as a non-beer spoiler. Moreover, the transmembrane protein HitA [16] has been identified only in two of the L. brevis beer-spoiler strains UCCLBBS449 and TMW1.2112. These observations reinforce the statement that involvement of these genes in beer survival and spoilage is not always verified as they are not consistently present in beer-spoiler organisms nor are always corresponding to beer spoilage ability if present in a strain [15]. The list of genes present only in $L$. brevis beer-spoiler strains shows that strains $L$. brevis TMW1.2108 and TMW1.2111 possess more than 90\% of these genes whereas L. brevis UCCLB95 only possesses one gene coding for the membrane transporter HorC (Table 6). The remainder of the L. brevis beer-spoiler strains carry approximately $50 \%$ of these particular genes (Table 6).

Out of these 25 unique genes shared among L. brevis beer-spoiler strains approximately $25 \%$ code for hypothetical proteins of unknown function. Meanwhile, 30\% of these genes appear to encode cell wall-associated proteins either as membrane transporters (MFS transporter, HorC) or as cell wall biosynthesis (lipopolysaccharide glycosyltransferases, acyltransferases). As mentioned above, a beer-spoiling strain would need to extrude toxic compounds using transporters and adapt its cell wall composition to survive the harsh beer environment. A smaller portion of these unique genes are linked to transcription regulation, replication or mobilome.

Interestingly, some of the plasmid-associated genes identified among $L$. brevis beer-spoiler strains in this analysis have also been highlighted previously as unique attributes of beer-spoiling strain plasmids [36]. The gene coding for the $\mathrm{CrcB}$ like-protein involved in ion transport was found on plasmid BSO 464-2 of the L. brevis beer-spoiler strain BSO 464 as well as a gene coding for enolase involved in glucose metabolism. A gene coding for cytosine deaminase is present in five out of the seven L. brevis beer-spoiler strains used in this analysis (Table 6) and was identified as a unique attribute on the plasmid pPECL-8 of the beer-spoiler Pediococcus claussenii ATCC BAA-344 [36]. Moreover, a plasmid-associated gene coding for a glycosyltransferase family 2 was highlighted in the analysis (Table 6), this protein was associated with excess $\beta$-glucan formation leading to a slimy ropy phenotype in the $L$. brevis beer-spoiler TMW1.2112 [37]. This slimy phenotype was observed in the L. brevis strain UCCLBBS124 first described in this study (Table 1), and the gene coding for the glycosyltransferase family 2 was identified on one of its plasmid UCCLBBS124_pB.

This overall examination of plasmid-associated genes shows the importance of extrachromosomal DNA in beer spoilage adaptation and opens new possibilities for understanding the beer spoilage process with an updated list of potential proteins of interest only present in $L$. brevis beer-spoiler strains.

\section{Conclusions}

The isolation and genome sequencing of six L. brevis strains combined with thirteen additional, publicly available $L$. brevis genomes allowed a comparative genome analysis of the $L$. brevis species. The deduced pan-genome of these $L$. brevis isolates appears to be in a closed state, indicating that the representatives used in this study are sufficient to describe the genetic diversity of the taxon. Throughout evolution, it appears that $L$. brevis strains specified and differentiated one from another by acquiring plasmids and prophages, despite for the presence of CRISPR-Cas and R/M systems which may have limited such foreign DNA invasion events. These latter systems are of relevance for future functional investigations that may necessitate the development of DNA transfer and/or mutagenesis tools. $L$. brevis strains represent a significant threat for the brewing industry being the most common cause of beer spoilage; however, this spoiling ability is strain specific. The comparative genome analysis performed here highlights that $L$. brevis strains with the ability to grow in beer possess a higher number of CDSs in their overall chromosomal sequences. This observation suggests a link to evolution and adaptation to beer in which the strain would have acquired novel genes and functions in order to adapt and survive in the harsh environment that beer represents. The role(s) of the "acquired" or beer-specific CDSs revealed that almost a quarter of these are linked to oxido-reduction reactions, possibly playing a role in the response to oxidative stress. Another $22 \%$ are linked to transcription regulation, $21 \%$ 
Table 6 List of genes specifically only present in plasmid sequences of at least three L. brevis strains characterized as beer-spoilers

\begin{tabular}{|c|c|c|c|c|c|c|c|}
\hline \multirow[t]{2}{*}{ COG category and protein function } & \multicolumn{7}{|c|}{ L. brevis beer-spoiler strains } \\
\hline & TMW1.2108 & TMW1.2111 & TMW1.2112 & TMW1.2113 & UCCLB95 & UCCLBBS124 & UCCLBBS449 \\
\hline & \multicolumn{7}{|c|}{ Defence mechanisms } \\
\hline \multirow[t]{2}{*}{ Membrane protein HorC } & + & + & + & - & + & + & + \\
\hline & \multicolumn{7}{|c|}{ Cell wall biogenesis } \\
\hline Lipopolysaccharide biosynthesis glycosyltransferase & + & + & + & + & - & + & + \\
\hline \multirow[t]{2}{*}{ Lipopolysaccharide biosynthesis glycosyltransferase } & + & + & + & + & - & + & + \\
\hline & \multicolumn{7}{|c|}{ Lipid transport and metabolism } \\
\hline Phospholipid-glycerol acyltransferase & + & + & + & + & - & + & + \\
\hline 1-acyl-sn-glycerol-3-phosphate acyltransferase & + & + & + & + & - & + & + \\
\hline \multirow[t]{2}{*}{ Fatty acid-binding protein DegV } & - & - & + & + & - & + & + \\
\hline & \multicolumn{7}{|c|}{ Carbohydrate transport and metabolism } \\
\hline Glycosyl transferase family 2 & + & + & + & - & - & + & - \\
\hline Enolase & + & + & - & - & - & - & + \\
\hline \multirow[t]{2}{*}{ MFS transporter } & + & + & + & + & - & - & - \\
\hline & \multicolumn{7}{|l|}{ Transcription } \\
\hline Sigma-70 region 4 family protein & + & + & - & - & - & - & + \\
\hline \multirow[t]{2}{*}{ Transcriptional regulator TetR family } & + & + & + & - & - & + & + \\
\hline & \multicolumn{7}{|c|}{ Nucleotide transport and metabolism } \\
\hline \multirow[t]{2}{*}{ Cytosine deaminase } & + & + & - & + & - & + & + \\
\hline & \multicolumn{7}{|c|}{ Inorganic ion transport and metabolism } \\
\hline \multirow[t]{2}{*}{ CrcB-like protein } & + & + & - & - & - & - & + \\
\hline & \multicolumn{7}{|c|}{ Replication, recombination and repair } \\
\hline Cytosine-specific methyltransferase & + & + & - & - & - & + & - \\
\hline \multirow[t]{2}{*}{ Initiator RepB protein } & + & + & - & - & - & - & + \\
\hline & \multicolumn{7}{|c|}{ Function unknown } \\
\hline Hypothetical protein & + & + & - & - & - & - & + \\
\hline Hypothetical protein & + & + & + & + & - & - & + \\
\hline Hypothetical protein & + & + & + & + & - & - & - \\
\hline Hypothetical protein & + & + & - & - & - & - & + \\
\hline Hypothetical protein & + & + & - & - & - & + & - \\
\hline Hypothetical protein & + & - & + & - & - & + & - \\
\hline \multirow[t]{2}{*}{ PemK family protein } & + & + & - & - & - & + & - \\
\hline & \multicolumn{7}{|l|}{ Mobilome } \\
\hline Transposase & + & + & - & - & - & + & \\
\hline Mobilization protein & + & + & - & - & - & - & + \\
\hline Mobilization protein & + & + & - & - & - & - & + \\
\hline
\end{tabular}

+: gene present, -: gene absent

encode cell surface proteins while $14 \%$ are encoding membrane transport related proteins and possibly associated to harmful compound extrusion encountered by the L. brevis strains when surviving and growing in beer. Additional genetic diversification of these L. brevis strains is expected to have occurred through plasmid acquisition that also likely contributes to beer adaptation. The plasmid content analysis of the different $L$. brevis beer-spoiler strains highlighted the presence of unique proteins shared among these strains. These proteins are mostly hypothetical proteins while approximately 30\% are linked to membrane transport, and cell-wall synthesis. These observations demonstrate the complexity of microorganisms' beer spoilage ability and suggests that 
adaptation of the L. brevis strain to beer is a complex process, not due to the action of only one specific gene, but more likely the intervention of a complex, multi-factorial response.

\section{Methods}

Isolation of $L$. brevis strains

Five distinct $L$. brevis strains (UCCLB521, UCCLB556, UCCLB95, UCCLBBS124 and UCCLBBS449) were isolated from the brewing environment, while SA-C12 had previously been isolated from silage [22]. The strains were characterized by evaluating their plasmid content as well as growth curve profiles in MRS broth or in beer at $30^{\circ} \mathrm{C}$. Plasmids were isolated after overnight growth of the L. brevis strains in MRS broth at $30^{\circ} \mathrm{C}$, cells were pelleted by centrifugation for $10 \mathrm{~min}$ at $5000 \mathrm{rpm}$ followed by lysozyme treatment $(30 \mathrm{mg} / \mathrm{mL}$ lysozyme in $\mathrm{TE}+25 \%$ sucrose) at $37^{\circ} \mathrm{C}$ for $30 \mathrm{~min}$. Plasmids were extracted using the GeneJET Plasmid Miniprep Kit (Thermo Scientific ${ }^{\mathrm{Tu}}$ ). Plasmid profiles of the different $L$. brevis isolates were analyzed using a $1 \%$ agarose gel. Growth curve profiles in MRS broth or in beer were performed at $30^{\circ} \mathrm{C}$ by hourly $\mathrm{OD}_{600 \mathrm{~nm}}$ measurements for a period of $55 \mathrm{~h}$. Moreover, colony morphology was recorded following growth on MRS agar plate at $30^{\circ} \mathrm{C}$.

\section{Sequencing and annotation}

L. brevis strains were streaked on MRS agar plates and grown at $30^{\circ} \mathrm{C}$ for $24 \mathrm{~h}$. For each L. brevis strain, a single colony was inoculated into MRS broth and grown overnight at $30^{\circ} \mathrm{C}$. Cells were pelleted by centrifugation at $5000 \mathrm{rpm}$ for $10 \mathrm{~min}$. The supernatant was removed and the pelleted cells were frozen at $-20^{\circ} \mathrm{C}$ prior sending for sequencing. Sequencing was performed using the PacBio SMRT next generation sequencing technology (performed by GATC Biotech, Germany). De novo genome assemblies were performed using the Pacific Biosciences SMRT Portal analysis platform. Open Reading Frame (ORF) or coding sequence (CDS) prediction was performed using Prodigal prediction software [38] and confirmed using BLASTX alignments [39]. Automatic annotations were refined using Artemis v16.0.0 where ORF predictions were manually checked, start codons adjusted and pseudogenes identified. Transfer RNA (tRNA) genes were predicted using tRNA-scan-SE v2.0 [40], while ribosomal RNA (rRNA) genes were identified using RNAmmer v1.2 [41]. The sixteen $L$. brevis genomes obtained from NCBI were re-annotated as described above in order to treat identically all sequenced genomes used in this study.

\section{Methylome analysis}

Following de novo genome assembly, the RS_Modification_and_Motif_Analysis.1 protocol of the SMRT Analysis portal was employed for base modification and methylated motif detection. This analysis was performed on L. brevis strains sequenced, assembled and annotated as part of this study. Methylation motifs with a score equal or higher than 40 (corresponding to a $P$-value of $<0.0001$ ) were considered specific and used for further analysis. ORFs of genomes were investigated for the presence of restriction/modification systems using the BLASTP alignment function of the REBASE database [42] (cut-off E-value of 0.0001; with at least $30 \%$ similarity over at least $80 \%$ of the sequence length). A comparative genome analysis was employed to associate the presence of $\mathrm{R} / \mathrm{M}$ system-encoding genes with the presence of methylation motif(s).

\section{Comparative genomics}

All protein sequence comparisons were performed using all-against-all, bi-directional BLAST alignments [39]. An alignment cut-off value of E-value 0.0001, and a similarity cut-off level of at least 30\% amino acid identity across $80 \%$ of the sequence length was used. Results were analyzed with the Markov Clustering Algorithm (MCL) [43] and proteins encoded were categorized in predicted functional groups based on COG (Clusters of Orthologous Groups) assignments [44].

\section{Phylogenetic analysis}

The supertree was prepared using the BLAST-based comparative approach described above in order to identify chromosomal orthologous proteins. The set of chromosomal orthologous proteins was concatenated for each strain and an ungapped alignment was performed using MUSCLE v3.8.31 [45]. The phylogenetic tree was computed using the maximum-likelihood method in PhyML v3.0 and bootstrapped employing 1000 replicates [46]. The final tree was visualized using MEGA7. A tree based on $16 \mathrm{~S}$ rRNA genes was constructed using clustalw and visualized via ITOL (Interactive Tree Of Life) [47]. The chromosome sequence of Enterococcus faecalis V583 (Accession: AE016830) was included as an outgroup.

\section{Pan/core-genome analysis}

The pan-core genome analysis of the above-mentioned $19 \mathrm{~L}$. brevis chromosomal sequences, was performed using PGAP v1.0 [48]. ORF content for each chromosome is classified in functional gene clusters using the Gene Family method. From this analysis a pan/core genome profile was generated.

\section{Genome accession numbers}

L. brevis 100D8: CP015338, L. brevis ATCC 367: CP000416, L. brevis BDGP6: CP024635, L. brevis KB290: AP012167, L. brevis NCTC13768: LS483405, L. brevis NPS-QW-145: CP015398, L. brevis SA-C12: CP031185, L. brevis SA-C12_pA: CP031186, L. brevis SA-C12_pB: CP031187, L. brevis SRCM101106: CP021674, L. brevis 
SRCM101174: CP021479, L. brevis TMW 1.2108: CP019734, L. brevis TMW 1.2111: CP019743, L. brevis TMW 1.2112: CP016797, L. brevis TMW 1.2113: CP019750, L. brevis UCCLB521: CP031208, L. brevis UCCLB521_pA: CP031209, L. brevis UCCLB521_pB: CP031210, L. brevis UCCLB521_pC: CP031211, L. brevis UCCLB521_pD: CP031212, L. brevis UCCLB521_pE: CP031213, L. brevis UCCLB556: CP031174, L. brevis UCCLB556_pA: CP031175, L. brevis UCCLB556_pB: CP031176, L. brevis UCCLB556_pC: CP031177, L. brevis UCCLB556_pD: CP031178, L. brevis UCCLB556_pE: CP031179, L. brevis UCCLB556_pF: CP031180, L. brevis UCCLB556_pG: CP031181, L. brevis UCCLB95: CP031182, L. brevis UCCLB95_pA: CP031183, L. brevis UCCLB95_pB: CP031184, L. brevis UCCLBBS124: CP031169, L. brevis UCCLBBS124_pA: CP031170, L. brevis UCCLBBS124_pB: CP031171, L. brevis UCCLBBS124_pC: CP031172, L. brevis UCCLBBS124_pD: CP031173, L. brevis UCCLBBS449: CP031198, L. brevis UCCLBBS449_pA: CP031199, L. brevis UCCLBBS449_pB: CP031200, L. brevis UCCLBBS449_pC: CP031201, L. brevis UCCLBBS449_pD: CP031202, L. brevis UCCLBBS449_pE: CP031203, L. brevis UCCLBBS449_pF: CP031204, L. brevis UCCLBBS449_pG: CP031205, L. brevis UCCLBBS449_pH: CP031206, L. brevis UCCLBBS449_pI: CP031207, L. brevis ZLB004: CP021456 and Enterococcus faecalis V583: AE016830.

\section{Abbreviations \\ BLAST: Basic Alignment Search Tool; CDS: Coding Sequence; COG: Cluster of Orthologous Group; CRISPR: Clustered Regularly Interspaced Short Palindromic Repeats; DMG: Diagnostic Marker Genes; ITOL: Interactive Tree Of Life; LAB: Lactic Acid Bacteria; MCL: Markov Clustering Algorithm; ORF: Open Reading Frame; QPS: Qualified Presumption of Safety; R/ M: Restriction/Modification; ROS: Reactive Oxygen Species; SDR: Short-chain Dehydrogenase/Reductase; SMRT: Single-Molecule-Real-Time sequencing}

\section{Acknowledgments}

Not applicable.

\begin{abstract}
Funding
Marine Feyereisen is the recipient of an Irish Research Council Enterprise Partnership Scheme postgraduate scholarship (Ref. No. EPSPG/2015/7). Douwe van Sinderen is supported by a Principal Investigator award (Ref. No. 450 13/IA/1953) through Science Foundation Ireland (SFI). Jennifer Mahony is in receipt of Starting Investigator Research Grant (SIRG) (Ref. No. 15/SIRG/ 3430) funded by Science Foundation Ireland (SFI). The funding bodies were involved in study design.
\end{abstract}

\footnotetext{
Availability of data and materials

All genome sequences analyzed during the current study are available from the National Centre for Biotechnology Information (NCBI) genome database. Additionally, all genomes sequenced during the current study have been deposited in the NCBI genome database. Accession numbers are as follow: $L$. brevis SA-C12: CP031185, L. brevis SA-C12_pA: CP031186, L. brevis SA-C12_pB: CP031187, L. brevis UCCLB521: CP031208, L. brevis UCCLB521_PA: CP031209, L. brevis UCCLB521_pB: CP031210, L. brevis UCCLB521_pC: CP031211, L. brevis UCCLB521_pD: CP031212, L. brevis UCCLB521_pE: CP031213, L. brevis UCCLB556: CP031174, L. brevis UCCLB556_PA: CP031175, L. brevis UCCLB556_pB: CP031176, L. brevis UCCLB556_PC: CP031177, L. brevis UCCLB556_pD: CP031178, L. brevis UCCLB556_pE: CP031179, L. brevis UCCLB556_PF: CP031180, L. brevis UCCLB556_pG: CP031181, L. brevis UCCLB95: CP031182, L. brevis UCCLB95_pA: CP031183, L. brevis UCCLB95_pB: CP031184, L. brevis UCCLBBS124: CP031169, L. brevis UCCLBBS124_pA:
}

CP031170, L. brevis UCCLBBS124_pB: CP031171, L. brevis UCCLBBS124_pC CP031172, L. brevis UCCLBBS124_pD: CP031173, L. brevis UCCLBBS449: CP031198, L. brevis UCCLBBS449_PA: CP031199, L. brevis UCCLBBS449_pB: CP031200, L. brevis UCCLBBS449_pC: CP031201, L. brevis UCCLBBS449_pD: CP031202, L. brevis UCCLBBS449_pE: CP031203, L. brevis UCCLBBS449_pF: CP031204, L. brevis UCCLBBS449_pG: CP031205, L. brevis UCCLBBS449_pH: CP031206, L. brevis UCCLBBS449_pl: CP031207.

\section{Author's contributions}

MF carried out sequence assembly, annotation and data analysis with the help of PK. MF performed experiments. RJR carried out the Methylome analysis. DVS, JM, TOS and JG provided materials and strains. MF, JM, TOS and DvS wrote the manuscript. All authors read and approved the final manuscript.

\section{Ethics approval and consent to participate}

Not applicable.

\section{Consent for publication}

Not applicable.

\section{Competing interests}

The authors declare that TOS and JG are employees of Heineken and supplied Lb. brevis strains UCCLB521, UCCLB556, UCCLB95, UCCLBBS124 and UCCLBBS449.

\section{Publisher's Note}

Springer Nature remains neutral with regard to jurisdictional claims in published maps and institutional affiliations.

\section{Author details}

${ }^{1}$ School of Microbiology, University College Cork, Cork, Ireland. ${ }^{2}$ APC Microbiome Ireland, University College Cork, Cork, Ireland. ${ }^{3} \mathrm{New}$ England BioLabs, Inc., Ipswich, MA, USA. ${ }^{4}$ HEINEKEN Global Supply Chain B.V, Zoeterwoude, The Netherlands.

Received: 4 December 2018 Accepted: 7 May 2019

Published online: 23 May 2019

\section{References}

1. Vos, P., G. Garrity, D. Jones, N.R. Krieg, W. Ludwig, F.A. Rainey, K.-H. Schleifer, and W. Whitman, Bergey's manual of systematic bacteriology: volume 3: the Firmicutes. 2011. 3: p. 464-511.

2. Kandler O. Carbohydrate metabolism in lactic acid bacteria. Antonie Van Leeuwenhoek. 1983;49(3):209-24.

3. Felis GE, Dellaglio F. Taxonomy of lactobacilli and Bifidobacteria. Current issues in intestinal microbiology. 2007:8(2):44-61.

4. Duar RM, Lin XB, Zheng J, Martino ME, Grenier T, Pérez-Muñoz ME, Leulier F, Gänzle $\mathrm{M}$, Walter J. Lifestyles in transition: evolution and natural history of the genus Lactobacillus. FEMS Microbiol Rev. 2017:41(Supp_1):S27-48.

5. Makarova K, Slesarev A, Wolf Y, Sorokin A, Mirkin B, Koonin E, Pavlov A, Pavlova N, Karamychev V, Polouchine N, Shakhova V, Grigoriev I, Lou Y, Rohksar D, Lucas S, Huang K, Goodstein DM, Hawkins T, Plengvidhya V, Welker D, Hughes J, Goh Y, Benson A, Baldwin K, Lee J, Díaz-Muñiz I, Dosti B, Smeianov V, Wechter W, Barabote R, Lorca G, Altermann E, Barrangou R, Ganesan B, Xie Y, Rawsthorne H, Tamir D, Parker C, Breidt F, Broadbent J, Hutkins R, O'Sullivan D, Steele J, Unlu G, Saier M, Klaenhammer T, Richardson P, Kozyavkin S, Weimer B, Mills D. Comparative genomics of the lactic acid bacteria. Proc Natl Acad Sci U S A. 2006;103(42):15611-6.

6. Fukao M, Oshima K, Morita H, Toh H, Suda W, Kim SW, Suzuki S, Yakabe T, Hattori M, Yajima N. Genomic analysis by deep sequencing of the probiotic Lactobacillus brevis KB290 harboring nine plasmids reveals genomic stability. PLoS One. 2013;8(3).

7. Salvetti E, Torriani S, Felis GE. The genus Lactobacillus: a taxonomic update. Probiotics and antimicrobial proteins. 2012;4(4):217-26.

8. Bergsveinson, J., V. Pittet, E. Ewen, N. Baecker, and B. Ziola, Genome Sequence of Rapid Beer-Spoiling Isolate Lactobacillus brevis BSO 464. 2015. 3(6).

9. Fraunhofer ME, Geissler AJ, Wefers D, Bunzel M, Jakob F, Vogel RF. Characterization of $\beta$-glucan formation by Lactobacillus brevis TMW 1.2112 isolated from slimy spoiled beer. Int J Biol Macromol. 2017. 
10. Sakamoto K, Konings WN. Beer spoilage bacteria and hop resistance. Int J Food Microbiol. 2003;89(2-3):105-24.

11. Vaughan A, O'Sullivan T, Van Sinderen D. Enhancing the microbiological stability of malt and beer - a review. J Inst Brew. 2005;111(4):355-71.

12. Bokulich NA, Bamforth CW. The microbiology of malting and brewing. Microbiology and molecular biology reviews : MMBR. 2013;77(2):157-72.

13. Sakamoto K, Margolles A, van Veen HW, Konings WN. Hop resistance in the beer spoilage bacterium Lactobacillus brevis is mediated by the ATP-binding cassette multidrug transporter HorA. J Bacteriol. 2001;183(18):5371-5.

14. lijima K, Suzuki K, Ozaki K, Yamashita H. horC confers beer-spoilage ability on hop-sensitive Lactobacillus brevis ABBC45cc. J Appl Microbiol. 2006; 100(6):1282-8.

15. Suzuki K, lijima K, Sakamoto K, Sami M, Yamashita H. A review of hop resistance in beer spoilage lactic acid bacteria. J Inst Brew. 2006;112(2):173-91.

16. Hayashi $\mathrm{N}$, Ito M, Horiike S, Taguchi H. Molecular cloning of a putative divalent-cation transporter gene as a new genetic marker for the identification of Lactobacillus brevis strains capable of growing in beer. Appl Microbiol Biotechnol. 2001;55(5):596-603.

17. Kant R, Blom J, Palva A, Siezen RJ, de Vos WM. Comparative genomics of Lactobacillus. Microb Biotechnol. 2011;4(3):323-32.

18. Claesson MJ, van Sinderen D, O'Toole PW. Lactobacillus phylogenomics-towards a reclassification of the genus. Int J Syst Evol Microbiol. 2008;58(Pt 12:2945-54.

19. Goh YJ, Klaenhammer TR. Genomic features of Lactobacillus species. Front Biosci (Landmark Ed). 2009;(14):1362-86.

20. Gupta PK. Single-molecule DNA sequencing technologies for future genomics research. Trends Biotechnol. 2008;26(11):602-11.

21. McCarthy A. Third generation DNA sequencing: Pacific Biosciences' single molecule real time technology. Chem Biol. 2010;17(7):675-6.

22. Deasy T, Mahony J, Neve H, Heller KJ, van Sinderen D. Isolation of a virulent Lactobacillus brevis phage and its application in the control of beer spoilage. J Food Prot. 2011;74(12):2157-61.

23. Horvath P, Barrangou R. CRISPR/Cas, the immune system of Bacteria and archaea. Science. 2010;327(5962):167-70.

24. Modrich P. Structures and mechanisms of DNA restriction and modification enzymes. Q Rev Biophys. 2009;12(3):315-69.

25. Jang $\mathrm{SH}$, Yoon $\mathrm{BH}$, Chang $\mathrm{HI}$. Complete nucleotide sequence of the temperate bacteriophage LBR48, a new member of the family Myoviridae. Arch Virol. 2011;156(2):319-22.

26. Bottacini, F., M. O'Connell-Motherway, J. Kuczynski, K.J. O'Connell, F. Serafini, S. Duranti, C. Milani, F. Turroni, G.A. Lugli, A. Zomer, D. Zhurina, C. Riedel, M. Ventura, and D. Sinderen, Comparative genomics of the Bifidobacterium breve taxon. BMC Genomics, 2014. 15

27. Kelleher P, Bottacini F, Mahony J, Kilcawley KN, van Sinderen D. Comparative and functional genomics of the Lactococcus lactis taxon; insights into evolution and niche adaptation. BMC Genomics. 2017;18(1):267.

28. Booth IR. Regulation of cytoplasmic pH in bacteria. Microbiol Rev. 1985; 49(4):359-78.

29. Cook GM, Russell JB. The effect of extracellular $\mathrm{pH}$ and lactic acid on $\mathrm{pH}$ homeostasis inLactococcus lactis andStreptococcus bovis. Curr Microbiol. 1994;28(3):165-8.

30. Siegumfeldt $H$, Rechinger KB, Jakobsen M. Dynamic changes of intracellular $\mathrm{pH}$ in individual lactic acid bacterium cells in response to a rapid drop in extracellular pH. Appl Environ Microbiol. 2000;66(6):2330-5.

31. Betteridge DJ. What is oxidative stress? Metabolism. 2000;49(2 Suppl 1):3-8.

32. van de Guchte $M$, Serror P, Chervaux C, Smokvina T, Ehrlich SD, Maguin E. Stress responses in lactic acid bacteria. Antonie Van Leeuwenhoek. 2002;82(1):187-216.

33. Kavanagh $\mathrm{KL}$, Jörnvall $\mathrm{H}$, Persson B, Oppermann U. Medium- and shortchain dehydrogenase/reductase gene and protein families: the SDR superfamily: functional and structural diversity within a family of metabolic and regulatory enzymes. Cell Mol Life Sci. 2008;65(24):3895-906.

34. Höper D, Völker U, Hecker M. Comprehensive characterization of the contribution of individual SigB-dependent general stress genes to stress resistance of Bacillus subtilis. J Bacteriol. 2005;187(8):2810-26.

35. Pumirat $P$, Boonyuen U, Vanaporn M, Pinweha P, Tandhavanant S, Korbsrisate $\mathrm{S}$, Chantratita N. The role of short-chain dehydrogenase/ oxidoreductase, induced by salt stress, on host interaction of B. pseudomallei. BMC Microbiol. 2014;14(1).

36. Bergsveinson J, Ziola B. Comparative genomic and plasmid analysis of beerspoiling and non-beer-spoiling Lactobacillus brevis isolates. Can J Microbiol. 2017;63(12):970-83.
37. Fraunhofer ME, Geissler AJ, Wefers D, Bunzel M, Jakob F, Vogel RF. Characterization of $\beta$-glucan formation by Lactobacillus brevis TMW 1.2112 isolated from slimy spoiled beer. Int J Biol Macromol. 2018;107:874-81.

38. Hyatt D, Chen G-L, LoCascio PF, Land ML, Larimer FW, Hauser LJ. Prodigal: prokaryotic gene recognition and translation initiation site identification. BMC bioinformatics. 2010;11(1):119.

39. Altschul S, Gish W, Miller W, Myers E, Lipman D. Basic local alignment search tool. J Mol Biol. 1990;215.

40. Schattner P, Brooks AN, Lowe TM. The tRNAscan-SE, snoscan and snoGPS web servers for the detection of tRNAs and snoRNAs. Nucleic Acids Res. 2005:33(suppl_2):W686-9.

41. Lagesen K, Hallin P, Rødland EA, Stærfeldt H-H, Rognes T, Ussery DW. RNAmmer: consistent and rapid annotation of ribosomal RNA genes. Nucleic Acids Res. 2007;35(9):3100-8.

42. Roberts RJ, Vincze T, Posfai J, Macelis D. REBASE—a database for DNA restriction and modification: enzymes, genes and genomes. Nucleic Acids Res. 2015;(43, Database issue):D298-9.

43. Enright AJ, Van Dongen S, Ouzounis CA. An efficient algorithm for largescale detection of protein families. Nucleic Acids Res. 2002;30(7):1575-84.

44. Tatusov RL, Galperin MY, Natale DA, Koonin EV. The COG database: a tool for genome-scale analysis of protein functions and evolution. Nucleic Acids Res. 2000:28(1):33-6.

45. Edgar RC. MUSCLE: multiple sequence alignment with high accuracy and high throughput. Nucleic Acids Res. 2004;32(5):1792-7.

46. Guindon S, Gascuel O, Rannala B. A simple, fast, and accurate algorithm to estimate large phylogenies by maximum likelihood. Syst Biol. 2003;52(5): 696-704.

47. Letunic I, Bork P. Interactive tree of life (iTOL) v3: an online tool for the display and annotation of phylogenetic and other trees. Nucleic Acids Res. 2016;44(W1):W242-5.

48. Zhao Y, Wu J, Yang J, Sun S, Xiao J, Yu J. PGAP: pan-genomes analysis pipeline. Bioinformatics. 2012;28.

49. Fukao M, Oshima K, Morita H, Toh H, Suda W, Kim S-W, Suzuki S, Yakabe T, Hattori M, Yajima N. Genomic analysis by deep sequencing of the probiotic Lactobacillus brevis KB290 harboring nine plasmids reveals genomic stability. PLoS One. 2013;8(3):e60521.

50. Wu Q Law YS, Shah NP. Dairy Streptococcus thermophilus improves cell viability of Lactobacillus brevis NPS-QW-145 and its $\gamma$-aminobutyric acid biosynthesis ability in milk. Sci Rep. 2015;5.

Ready to submit your research? Choose BMC and benefit from:

- fast, convenient online submission

- thorough peer review by experienced researchers in your field

- rapid publication on acceptance

- support for research data, including large and complex data types

- gold Open Access which fosters wider collaboration and increased citations

- maximum visibility for your research: over $100 \mathrm{M}$ website views per year

At $\mathrm{BMC}$, research is always in progress.

Learn more biomedcentral.com/submissions 